\title{
EDUCATION POLICIES IN PRE-UNIVERSITY EDUCATION OF \\ THE REPUBLIC OF KOSOVO FOR NON-MAJORITY COMMUNITIES OF ROMA, ASHKALI AND EGYPTIAN
}

\author{
Maliqe MULOLLI - JAHMURATAJ, PhD. C. \\ 1 South East European University, Faculty of Education, Governance and Public Administration Department, maliqem @ gmail.com
}

\begin{tabular}{ll}
\hline Article history: & A b s t r a c t \\
$\begin{array}{l}\text { Accepted } 20 \text { March } 2020 \\
\text { Available online } 31 \text { April } 2020\end{array}$ & The Republic of Kosovo is a country that observes all the rights and obligations of its subjects with \\
& no discrimination in national, racial, linguistic sense. Even though we have these rights in place, in \\
Keywords: & practice the situation is different and not very positive. This is since the non-majority communities \\
Inclusion, & Roma, Ashkali and Egyptian in Kosovo face several problems in different areas, especially when it \\
Children from Non-Majority & comes to their right on integration to education. This paper will address and evaluate current policies \\
Communities of Roma, & and legislation of Kosovo for inclusion in education as a condition for completion of the education \\
Ashkali and Egyptian, & system.
\end{tabular}

Education Policy,

Pre-University Education.

\begin{abstract}
This paper will be developed by considering the assessment of the Constitution and relevant legislation referring to the right to education for non-majority communities. Given all this legislation, it will be assessed in harmony with the practical problems that exist regarding access to the education system for non-majority communities. Therefore, this paper aims to bring innovation in this field of research aiming to identify how much the Republic of Kosovo is keeping a pace with the standards for inclusion in the education system, what are the reasons that in current state of play we do not have a satisfactory inclusion in the education by category of children from non-majority communities of Roma, Ashkali and Egyptian in pre-university education.
\end{abstract}

1. Inclusion of children from non-majority communities of Roma, Ashkali and Egyptian in education system as a constitutional right with the Republic of

\section{Kosovo}

The Republic of Kosovo is oriented towards the highest universal values of the democratic world, being a direct implementor of international mechanisms that enable the observance of human rights, equality, non-discrimination and inclusion in public and social life for all citizens of Republic of Kosovo. To prove this orientation, the Republic of Kosovo, starting with the Constitution, Laws and other international instruments, has envisaged an equal treatment for all its citizens irrespective of their nation, nationality, religion or other issues that make them different from others. The Constitution of the Republic of Kosovo stipulates that: "The Republic of Kosovo is a state of its citizens.
The Republic of Kosovo exercises its authority based on the respect for human rights and freedoms of its citizens and all other individuals within its borders" (Constitution of the Republic of Kosovo, Article 1, paragraph 2). As provided in the Constitution, every citizen of the Republic of Kosovo is provided with a Constitutional assurance that the Republic of Kosovo is their state and the exercise of authority is based on the highest values of the civilized world based on human rights and freedoms. This is where it stems out interrelation of every citizen with the Republic of Kosovo and the mutual obligations, they have towards each other in terms of functioning of the state and establishing of a better living conditions and well-being for all its citizens.

The Republic of Kosovo is a state where the form of Governance and power sharing is stipulated in its Constitution and it: "Kosovo is a democratic Republic based on the principle of separation of powers and the checks and balances among them as provided in 
this Constitution. "( Constitution of the Republic of Kosovo, Article 4, paragraph 1 ). This clearly defines the form of government and that of the separation of powers that is in place for the state to be functional and accountable. What is related to the establishing of better living conditions and well-being, including the education system in Kosovo, is the responsibility of the Government Pillar which stipulates that: "The Government of the Republic of Kosovo is responsible for implementation of laws and state policies and is subject to parliamentarian control." ( Constitution of the Republic of Kosovo, Article 4, paragraph 4 ). From the mandate vested by Constitution, the Government is the authority that is initially responsible for drafting and proposing policies through draft laws, which are then approved by the Assembly of the Republic of Kosovo. The Government of the Republic of Kosovo is also responsible for the development, reform of the education system in the Republic of Kosovo, initially assessing the situation followed by creation of policies and legal infrastructure that governs, reforms and steers the education system in the Republic of Kosovo. The right to education is a constitutional right for every citizen of the Republic of Kosovo, as envisaged in the Constitution: "Every person enjoys the right to free basic education. Mandatory education is regulated by law and funded by public funds. Public institutions shall ensure equal opportunities to education for everyone in accordance with her/his specific abilities and needs." ( Constitution of the Republic of Kosovo, Article 47, paragraph 1 and 2). This constitution provides for the assurance of every citizen in the Republic of Kosovo who enjoys the right to education by providing them equal opportunities for education. This assurance for the right to education is also a constitutional and legal assurance for the citizens of the Republic of Kosovo who belong to non-majority communities of Roma, Ashkali and Egyptian. By establishing this legal assurance about the right to education for every citizen, the Republic of Kosovo has proven to be a state that within its legal system has incorporated universal human rights values and proves that it is on the right track also with regards in respecting the international mechanisms for which it is obliged to implement and incorporate in the framework of its national policymaking and education legislation.

The State of the Republic of Kosovo, in order to keep a pace with the universal values of the democratic world, within its Constitution has determined the direct implementation of international agreements and instruments such as the "Universal Declaration of Human Rights; The European Convention for the Protection of Human Rights and Fundamental Freedoms and its Protocols; The International Covenant on Civil and Political Rights and its Protocols; Council of Europe Framework Convention for the Protection of National Minorities; Convention on the Elimination of All Forms of Racial Discrimination;
Convention on the Elimination of All Forms of Discrimination against Women; Convention on the Rights of the Child; Convention against Torture and Other Cruel, Inhuman or Degrading Treatment or Punishment" ( Constitution of the Republic of Kosovo, Article 22 ). All these international instruments are directly applicable in the Republic of Kosovo and have priority over the domestic legislation, which shows the orientation and values that the state of the Republic of Kosovo aims to meet in the future.

These international mechanisms apply to every area as well as in education, and specifically to the rights of the citizens of the Republic of Kosovo from non-majority communities of Roma, Ashkali and Egyptian for their undeniable right to education. The right to education and inclusion in the education system of the Republic of Kosovo is also guaranteed under these mechanisms that are directly embedded into the Constitution of the country and ensure that every citizen is equal in every respect as well as in education.

Non-majority communities of Roma, Ashkali and Egyptian in the Republic of Kosovo have rights that provide them with equal treatment without being discriminated against and impeding their identity, in addition to being equal, they also enjoy special rights. These rights are also enshrined in the Constitution of the Republic of Kosovo, which stipulates that "Residents belonging to the same national or ethnic, linguistic, or religious group traditionally present on the territory of the Republic of Kosovo (Communities) shall have specific rights as set forth in this Constitution in addition to the human rights and fundamental freedoms provided in chapter II of this Constitution." ( Constitution of the Republic of Kosovo, Article 57, paragraph 1 ). The will for equal and special treatment of Roma, Ashkali and Egyptian non-majority communities has materialized as constitutional category, so this is the value that the state of Kosovo possesses in terms of the rights of non-majority communities of Roma, Ashkali and Egyptian. When referring specifically to the right to education of non-majority communities of Roma, Ashkali and Egyptian, the Constitution provides for a good position and that :"Members of communities shall have the right, individually or in community, to: express, maintain and develop their culture and preserve the essential elements of their identity, namely their religion, language, traditions and culture; receive public education in one of the official languages of the Republic of Kosovo of their choice at all levels; receive pre-school, primary and secondary public education, in their own language to the extent prescribed by law, with the thresholds for establishing specific classes or schools for this purpose being lower than normally stipulated for educational institutions; establish and manage their own private educational and training establishments for which public financial assistance 
may be granted, in accordance with the law and international standards; use their language and alphabet freely in private and in public; Use their language and alphabet in their relations with the municipal authorities or local offices of central authorities in areas where they represent a sufficient share of the population in accordance with the law. The costs incurred by the use of an interpreter or a translator shall be borne by the competent authorities " ( Constitution of the Republic of Kosovo, Article 59, paragraph 1,2,3,4,5,6). From the stipulation of these rights, it can be concluded that there is no discrimination against members of non-majority communities Roma, Ashkali and Egyptian in Kosovo but they are very good positioned in constitutional and legal area, so this is a value that the The Republic of Kosovo holds and considers it to be competitive with the most democratic countries in the world.

\section{Legislation stipulating the rights to education and inclusion of non-majority communities of Roma, Ashkali and Egyptian in the Republic of Kosovo}

The area of education, as one of the most important areas of the country is specifically governed by the relevant legislation, which aims to establish an education system that will serve the education and preparation of future generations for the labor market and development of society. Communities in the Republic of Kosovo are protected and promoted for equal opportunities, as stipulated in the following: "All persons belonging to communities shall have the right to receive public education at all levels in one of the official languages of Kosovo of their choice. Persons belonging to communities are entitled to pre-school, primary, secondary public education in their own language, even if it is not an official language. The Government of Kosovo shall establish reasonable and viable thresholds for establishing specific classes or schools operating in community languages. The minimum threshold for such classes or schools shall be lower than thresholds normally stipulated for educational institutions and classes. The maximum thresholds shall correspond with the established thresholds normally stipulated for school classes. This shall be regulated by law." ( Law no. 03 / 1-047 on the Protection and Promotion of the Rights of Communities and their Members in the Republic of Kosovo, Article 8, paragraph). This is an assurance that is governed by law and guarantees communities the education in their language as their fundamental right. In case in point we are entitled to the right to education as a right in principle, while it is regulated in detail with relevant legislation in force which will be addressed in the following of this paper.
Within the framework of the regulation of the education system through relevant legislation, the regulation of the education and training of members of non-majority communities of Roma, Ashkali and Egyptian in Kosovo has not been overlooked. Their rights to education are specified and regulated in the field of education as constitutional and legal rights. Therefore, the right to education starting from preschool is stipulated: " In the places of mixed population, preschools institutions shall provide education in minorities language as well, conform constitutional framework and special Laws." ( Law no. 02 / L-52 on Preschool Education, Article 5, paragraph 2). The non-majority communities of Roma, Ashkali and Egyptian through this right are entitled to have access to pre-school education in their language as a legal category constituting best evidence manifesting the rights of non-majority communities Roma, Ashkali and Egyptian to education in their language. The right of non-majority communities Roma, Ashkali and Egyptian to education is a legal category since pre-school and on. This fact shows that the rights of non-majority Roma, Ashkali and Egyptian communities in the Republic of Kosovo from their definition in the Constitution of the country, through relevant legislation, are specified and operationalized in detail in order to be observed as their fundamental rights. This proves once again the commitment of the state of the Republic of Kosovo, in terms of defining their rights and their norm in detail within the relevant legislation in force.

In addition to the rights to education, non-majority communities Roma, Ashkali and Egyptian are also part of the mechanisms related to the education system in the Republic of Kosovo, being in the function of protecting the rights of non-majority communities of Roma, Ashkali and Egyptian. The Non-majority communities of Roma, Ashkali and Egyptian communities within the education system are also part of the Kosovo Parents Council, where, and this is stipulated in "The Ministry issues a by-law on the work of the KPC, the procedures for appointing and electing its members, always involving members of non-majority communities" ( Law no. 04 / L-032 on Pre-University Education in the Republic of Kosovo, Article 16, paragraph 3). Even in this mechanism that is part of the education system, non-majority communities Roma, Ashkali and Egyptian are represented and are part of decision-making which is in function of capacity building and rights in the education system for non-majority Roma, Ashkali and Egyptian communities. Being part of this mechanism, non-majority communities of Roma, Ashkali and Egyptian are also part of those mechanisms that have the political scope to make, monitor and develop the education system in Kosovo. In addition to this mechanism at the national level, this right also belongs to the lower one that is the governing council of the public education and training institution stipulating that 
"three (3) representatives of parents, including at least one representative of non-majority communities in the municipality if there are any students from those communities in that institution" ( Law no. 04 / L-032 on Pre-University Education in the Republic of Kosovo, Article 17, paragraph 2, subparagraph 2.1 ). This mechanism also provides for the representation of non-majority Roma, Ashkali and Egyptian to each public education institution, enabling them to be part of the governance of the public education institution.

The importance and the stipulation of the right to education of non-majority communities of Roma, Ashkali and Egyptian in Kosovo is also envisaged with the Competences and Responsibilities of the Ministry on Provision of Higher Education, where: "In the exercise of its responsibilities and duties under this law, the Ministry respects and promotes the rights of communities and their members, as set forth in the Law on the Protection and Promotion of the Rights of Communities and their Members in Kosovo." ( Law no. 04 / L-037 on PreUniversity Education in the Republic of Kosovo, Article 6, paragraph 2).

Regarding inclusion in the education system for non-majority communities Roma, Ashkali and Egyptian communities, the Republic of Kosovo through its education system also governs the aspect of the National Qualification, which is based on the National Qualifications Framework, governed by the National Qualifications Authority. This is stipulated in: "The National Qualifications Authority established under the provisions of this Law shall establish and maintain a comprehensive framework of qualifications." ( Law no. 03 / L-060 on Preschool Education, Article 3, paragraph 2 ). Even in course of governing the specific areas of education, the concept of the Republic of Kosovo is to have inclusiveness, as for the specific part of the education system of qualifications which is also addressed from the perspective of inclusiveness. In terms of its importance, inclusiveness is also defined in terms of defining competencies within institutions for the education system in Kosovo. We find such stipulations within the competences of the Ministry of Education, Science and Technology, which among other things discharges the following responsibilities: "to develop a comprehensive library system, which will include University and and school libraries;" ( Law no. 03 / L-068 on Pre-University Education in the Republic of Kosovo, Article 3, item 1; ). The importance of inclusion as a right is also demonstrated by the serious approach of the state of the Republic of Kosovo towards inclusion. We also have this concept regarding vocational training as a legal category regulated by the relevant legislation in force. The concept of inclusion is also intertwined with regard to vocational training in the Republic of Kosovo, namely the principles of vocational education and training, where, among other, it is clearly defined as follows: 1. The principles of vocational education and training (hereinafter VET) are: 1.1. inclusiveness; ... " ( Law no. 04 / L138 on Vocational Education and Training, Article 3, paragraph 1, sub-paragraph 1.1). In addition to the fact that inclusion takes up sufficient space in the relevant Constitutional and legal imperative provisions, we also have importance and determination in the part of the principles that are the correct directions and orientations that the educational system of the Republic of Kosovo and the aspect of inclusiveness is heading to.

\section{The Current State of Play in the education system in terms of inclusion of non-majority communities of Roma, Ashkali and Egyptian}

The non-majority communities of Roma, Ashkali and Egyptian in Kosovo face several problems in different areas, especially when it comes to their integration into the right to education. Challenges and Difficulties for Non-majority Communities Roma, Ashkali and Egyptian are present s of the census stage, language and acceptance by majority communities and it continues with the large socio-economic differences between majority and non-majority communities of Roma, Ashkali and Egyptian. The non-majority communities of Roma, Ashkali and Egyptian in Southeast Europe also have problems of this nature. However, the developments in the early 1990s in Kosovo have left the access to education of these non-majority communities of Roma, Ashkali and Egyptian even more disadvantaged. The position of non-majority communities of Roma, Ashkali and Egyptian in Kosovo has become more difficult due to the recent war in the country where the population was displaced abroad. Approximate estimates from the UN indicate that after the 1999 conflict, the share of non-majority communities of Roma, Ashkali and Egyptian in the population of Kosovo decreased from 100,000 to $35-40,000$ members, which significantly affected the inclusion of non-majority communities of Roma, Ashkali and Egyptian in the education system. Although some time has elapsed since, the non-majority communities of Roma, Ashkali and Egyptian still face numerous problems such as their socioeconomic status, the phenomena of marginalization, discrimination and segregation. According to the latest data from the Education Information Management System (EMIS) of year 2005/06, from pre-school to upper secondary level, the number of children of non-majority communities of Roma, Ashkali and Egyptian involved is 4527 , or $1.1 \%$ visa-vis majority community, while according to data from the Ministry of Public Services of May 2007 the number of teaching staff from non-majority communities of Roma, Ashkali and Egyptian employed in education is 140 in total or $0.53 \%$, visa-vis the majority 
community. "Overall, if we take the data from the "Roma Decade" and by comparing it with neighboring countries, the number of children who have completed upper secondary level of education is $4.5 \%$, while in Albania is $4.3 \%$, in Serbia 9\%, in Macedonia $11.6 \%$ and in Montenegro it is $3.7 \%$.Implementation of this document will mobilize all relevant structures to pave the way for non-majority communities o Roma, Ashkali and Egyptian for full integration, which will enable non-majority communities of Roma, Ashkali and Egyptian to inclusion, preservation and integration, promotion, development and promotion of their identity, tradition and culture.

Current state of education of non-majority communities of Roma, Ashkali and Egyptian as well as Partial integration of nonmajority communities of Roma, Ashkali and Egyptian into education during analyzes of the position of non-majority communities of Roma, Ashkali and Egyptian in Kosovo the main factors that have influenced the partial integration of these communities into society were identified. Inadequate mobilization of government bodies, limited government and donor funding, scarce campaigns on the importance of education, lack of initiatives to advocate and lobby for the rights of nonmajority communities of Roma, Ashkali and Egyptian are among the key factors that have influenced the partial inclusion of members of the non-majority communities of Roma, Ashkali and Egyptian in Kosovo. Despite the fact that after the conflict in Kosovo, several initiatives have been taken to create a positive climate in the classroom and at school, then programs to motivate students to attend school regularly, such as programs to eliminate illiteracy, fast-paced learning, non-formal education programs and quotas for increasing enrollment in secondary and university education, bringing back to school those who have dropped out of school, concerning remains the fact the number of children involved in pre-university and university education such as and the number of children dropping out and not finishing school is very high. Disadvantaged socio-economic status, low number of educators and teachers from non-majority communities of Roma, Ashkali and Egyptian, lack of education in the Roma language, difficulties in mastering the official language at the beginning of schooling, as well as prejudices and stereotypes towards these communities present some of the other barriers that have made the inclusion of members of these communities in education continue to be at a very low level. Unsatisfactory participation of non-majority communities of Roma, Ashkali and Egyptian in education in Kosovo in the last 7-8 years resulted that children of non-majority communities of Roma, Ashkali and Egyptian in some settlements non-majority communities feel unsafe to continue their education within the regular full-time education system. This has led to the creation of an improvisational education service, which continues to operate in camps like
Gjilan and Plemetin camps, which operate in poor working conditions, in some communities with unqualified teachers and in very difficult conditions. The level of teaching and learning at those school has been very low and often not in line with the regular education system, which has prevented students from transferring to regular education. Insufficient cooperation between the Ministry of Education, Science and Technology and non-majority communities of Roma, Ashkali and Egyptian civic society organizations dealing with education issues has made the education authorities unaware of the difficulties and problems they face, which has led to a lack of transparency in making decisions of interest to these communities. Poverty levels, concepts and low levels of education of their parents, inadequate involvement in preschool education, lack of alternative education programs for members of the non-majority communities of Roma, Ashkali and Egyptian are other factors for non-inclusion of these communities in education. The number of children from non-majority communities of Roma, Ashkali and Egyptian who are not enrolled on time, and those who drop out of school is high.

The Ministry of Education, Science and Technology and the OSCE for several years have been providing intensive learning programs for students who have dropped out of school. This type of teaching is offered as an alternative to continuing and completing compulsory education. Many children, due to their difficult economic situation, are forced to drop out of school to work for their parents. The prejudices and stereotypes towards members of non-majority communities of Roma, Ashkali and Egyptian are also evident in the education system, which reflects discrimination against students and parents of these communities. Given that education is a necessary condition for competition in the labor market, it is an imperative for members of non-majority communities of Roma, Ashkali and Egyptian to complete at least primary and secondary education. In order to achieve this, the strategy envisages the development of supportive policies such as: scholarships, quotas for children of non-majority communities of Roma, Ashkali and Egyptian, in order to continue their studies in various fields. Competition in the labor market requires that members of the non-majority communities of Roma, Ashkali and Egyptian be educated and professionally prepared to get a job. Although Kosovo has specific anti-discrimination legislation while education legislation prohibits all forms of discrimination and segregation, there are still cases of discrimination and segregation in practice against members of non-majority communities of Roma, Ashkali and Egyptian.” ( Strategy for the Integration of Roma, Ashkali and Egyptian Communities in Kosovo, Education Component 2007-2017, Ministry of Education, Science and Technology).

\section{Conclusions}


The Republic of Kosovo is an exemplary state in terms of embedding international mechanisms for the protection of human rights and freedoms, embedding these mechanisms directly into the Constitution of the Republic of Kosovo and giving them priority over domestic legislation.

The rights of non-majority communities of Roma, Ashkali and Egyptian are advanced with no distinction from the rights of majority population of the country, where these rights are also constitutional and legal categories, which set out in detail the rights of communities and the obligations of the State of the Republic of Kosovo to exercise these rights.

For non-majority communities of Roma, Ashkali and Egyptian in the Republic of Kosovo, the right to education in the language of communities constitutes a legal category which provides them with the opportunity to use their language and alphabet as fundamental and rights for the development and emancipation of a community subject to their culture and tradition.

The Republic of Kosovo allocates adequate budget for the member's non-majority communities of Roma, Ashkali and Egyptian so they can exercise their fundamental right to education.

The use of native language is of a great interest to non-majority communities of Roma, Ashkali and Egyptian, as provided by the Constitution and legislation of the Republic of Kosovo, that the use of native languages is a fundamental right of non-majority communities of Roma, Ashkali and Egyptian.

As far as the participation of non-majority communities of Roma, Ashkali and Egyptian $\mathrm{c}$ in educational mechanisms in the Republic of Kosovo, they are represented in every mechanism that enables them to present and defend their rights in the field of education.

Notwithstanding the fact that the rights of non-majority community of Roma, Ashkali and Egyptian and in particular that of education, are stipulated by the Constitution and the relevant legislation in force, there are challenges and problems in practice with regard to the overall implementation of the legislation, as a result of the lack of full cooperation of the communities, and in particular of the Serbian community with the institutions of the Republic of Kosovo.

Regarding the right to education for non-majority communities of Roma, Ashkali and Egyptian, this also poses some challenges in terms of dropout rates, which is a high figure, for students from non-majority communities of Roma, Ashkali and Egyptian.
The right and access to the education system is also related to the economic and social conditions of the non-majority communities of Roma, Ashkali and Egyptian, which for some communities the economic conditions are poor and these have an impact on access to education as a fundamental right to their development.

The non-majority communities of Roma, Ashkali and Egyptian must get it right that the Republic of Kosovo is their country, therefore they should feel equal in being active in planning and exercising their rights to education and community development.

\section{References}

1. Constitution of the Republic of Kosovo, https://gzk.rks.gov.net/ActDocumentDetail.aspx?ActID=3 702 ;

2. Law no. 03 / 1-047 on the Protection and Promotion of the Rights of Communities and their Members in the Republic of Kosovo, https://gzk.rksgov.net/ActDocumentDetail.aspx?ActID=2531;

3. Law no. 02 / L-52 on Preschool Education, https://gzk.rks-

gov.net/ActDocumentDetail.aspx?ActID=2401;

4. Law no. 04 / L-032 on Pre-University Education in the Republic of Kosovo, https://gzk.rksgov.net/ActDocumentDetail.aspx?ActID=2770;

5. Law no. 04 / L-037 on Pre-University Education in the Republic of Kosovo, https://gzk.rksgov.net/ActDocumentDetail.aspx?ActID=2761;

6. Law no. 03 / L-060 for National Qualifications, https://gzk.rksgov.net/ActDocumentDetail.aspx?ActID=2606;

7. Law no. 03 / L-068 on Pre-University Education in the Republic of Kosovo, https://gzk.rksgov.net/ActDocumentDetail.aspx?ActID=2543;

8. Law no. 04 / L-138 on Vocational Education and Training, $\quad$ https://gzk.rksgov.net/ActDocumentDetail.aspx?ActID=8676;

9. Strategy for the Integration of Roma, Ashkali and Egyptian Communities in Kosovo, Education Component 2007-2017, Ministry of Education, Science and Technology, https://masht.rksgov.net/uploads/2015/05/strategjia-shqip-07017.pdf. 